Policy Brief

\title{
The Pacific oyster \\ - a new Nordic food \\ resource and a basis \\ for tourism
}

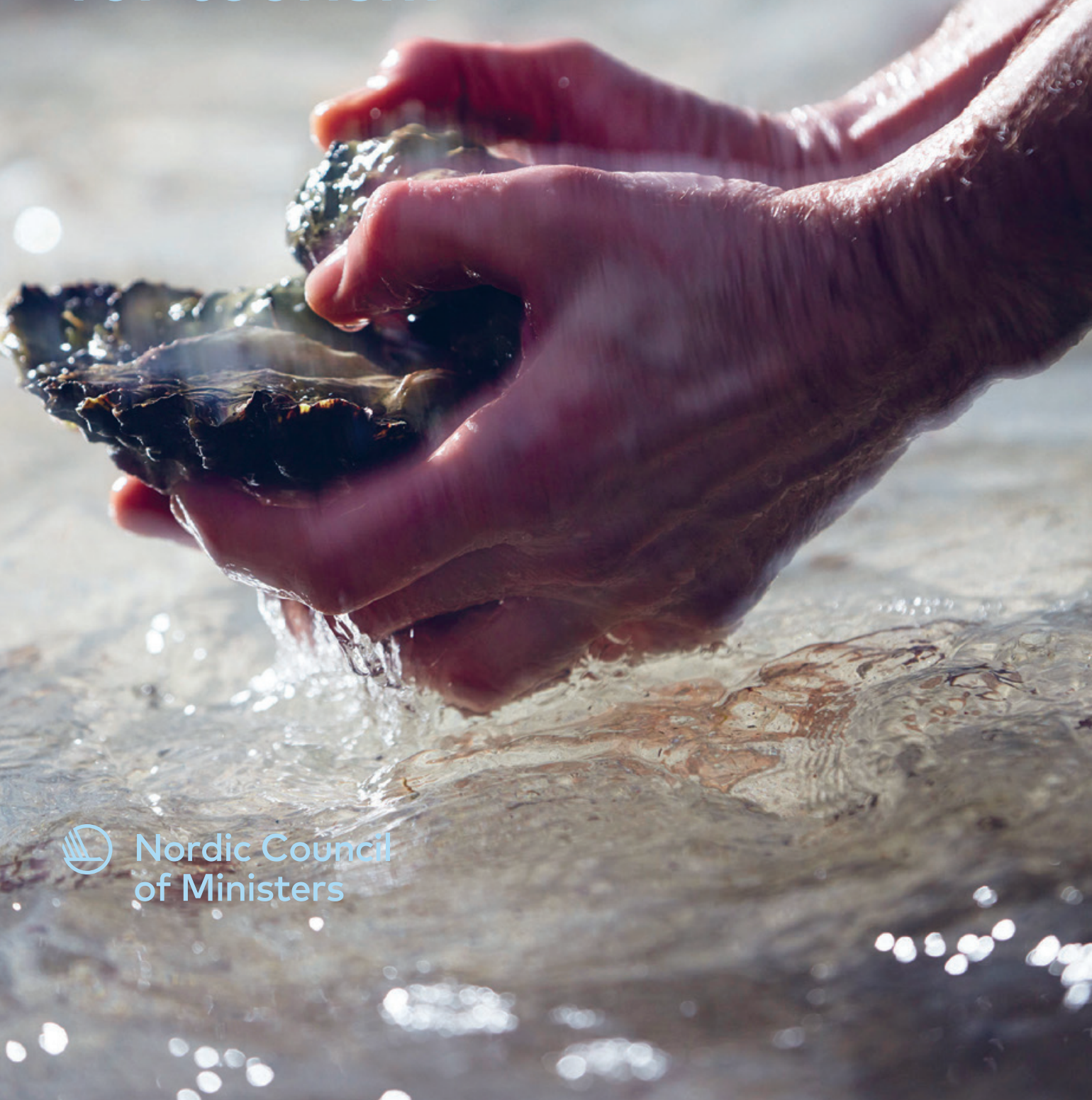


Policy Brief: The Pacific oyster - a new nordic food resource and a basis for tourism

Stein Mortensen, Per Dolmer, Åsa Strand, Lars-Johan Naustvoll and Ane Timenes Laugen

Nord 2019:015

ISBN 978-92-893-6121-7 (PRINT)

ISBN 978-92-893-6122-4 (PDF)

ISBN 978-92-893-6123-1 (EPUB)

http://dx.doi.org/10.6027/Nord2019-015

(c) Nordic Council of Ministers 2019

Layout: Mette Agger Tang

Cover photo: Øystein Klakegg

Print: Rosendahls

Printed in Denmark

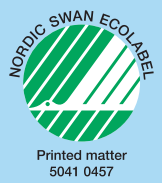

\section{Nordic co-operation}

Nordic co-operation is one of the world's most extensive forms of regional collaboration, involving Denmark, Finland, Iceland, Norway, Sweden, the Faroe Islands, Greenland, and Åland.

Nordic co-operation has firm traditions in politics, the economy, and culture. It plays an important role in European and international collaboration, and aims at creating a strong Nordic community in a strong Europe.

Nordic co-operation seeks to safeguard Nordic and regional interests and principles in the global community. Shared Nordic values help the region solidify its position as one of the world's most innovative and competitive.

\section{Nordic Council of Ministers \\ Nordens Hus \\ Ved Stranden 18 \\ DK-1061 Copenhagen \\ www.norden.org}

Download and order Nordic publications from www.norden.org/nordpub 


\section{Policy Brief}

\section{The Pacific oyster \\ - a new Nordic food resource and a basis for tourism}

\section{Content}

05 The Pacific oyster - friend or foe?

07 The dispersal of oysters and their environmental effects

08 Mitigation of invasive aquatic species

09 Commercial exploitation of Pacific oysters in Scandinavia

11 Regional oysters - or the meaning of merroir

12 Challenges

14 Conclusions and recommendations

15 Selected literature 
.

-

$e^{2}$

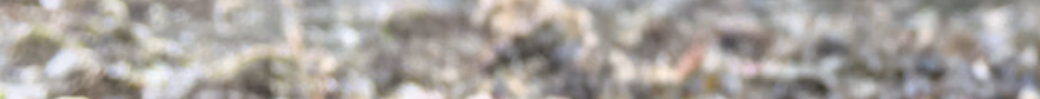
That

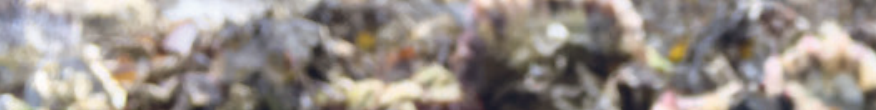

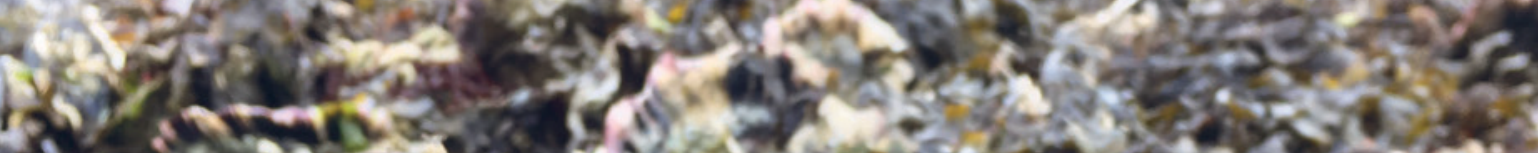

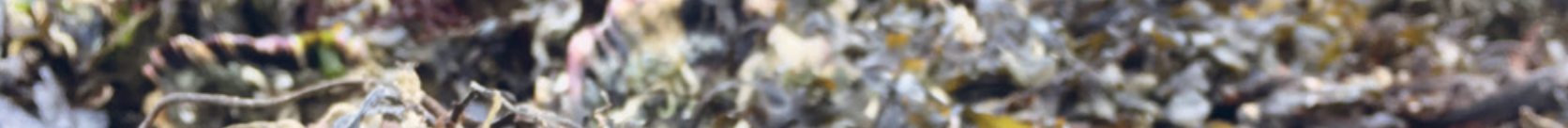

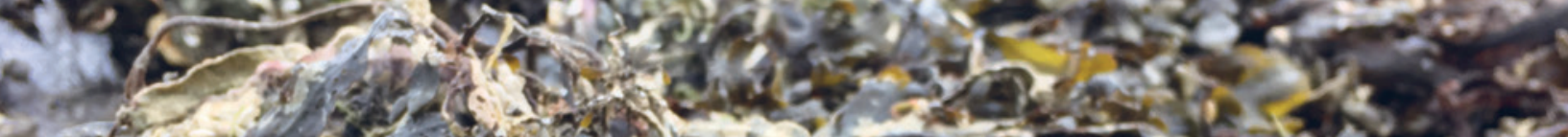
J.

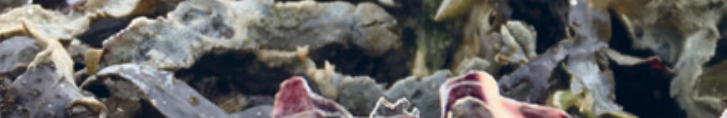

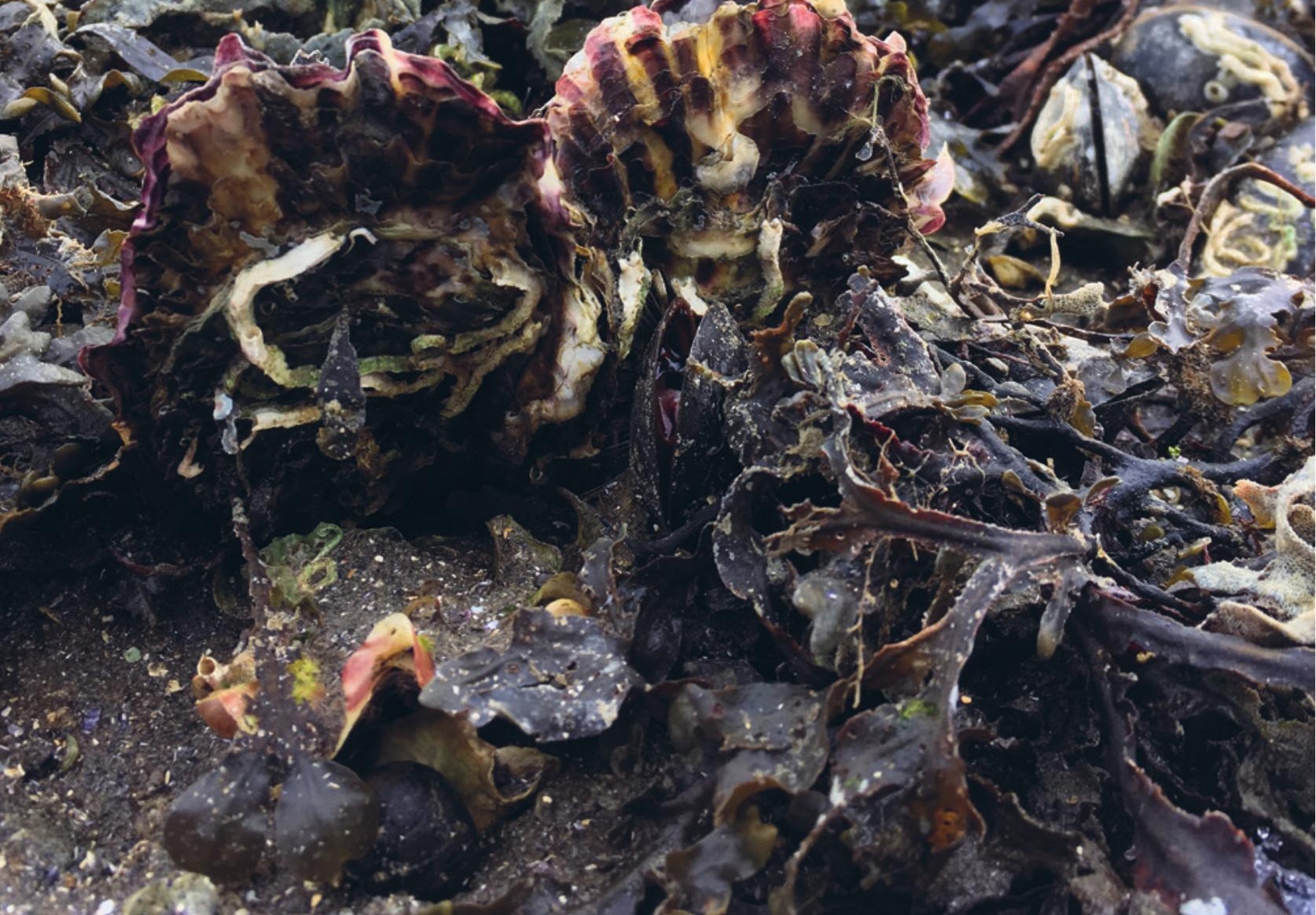

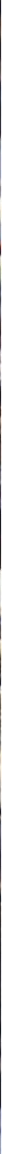




\section{The Pacific oyster - friend or foe?}

Since 2007, the Pacific oyster has established self-sustaining populations in Scandinavian coastal waters. The species is considered alien and invasive and dense populations may cause changes in benthic habitats. It is, however, also one of the world's most important aquaculture species, and there is a growing interest in using the Scandinavian populations as a new marine resource.

To release the commercial potential, there is an urgent need for a better understanding of the oyster's effect on the ecosystem and a clarification of several legal matters, as well as establishment of management practices for harvesting and marketing these oysters. Production methods and food control measures must also be in place to ensure that only safe and healthy oysters are placed on the market.

This Policy brief gives a summary of the status for the Pacific oyster in Scandinavia and presents recommendations for the future work and management of Pacific oysters in the Nordic countries. 
Pacific oyster reefs have built up in the Danish Wadden

Sea.

Photo: Per Dolmer

$\rightarrow$

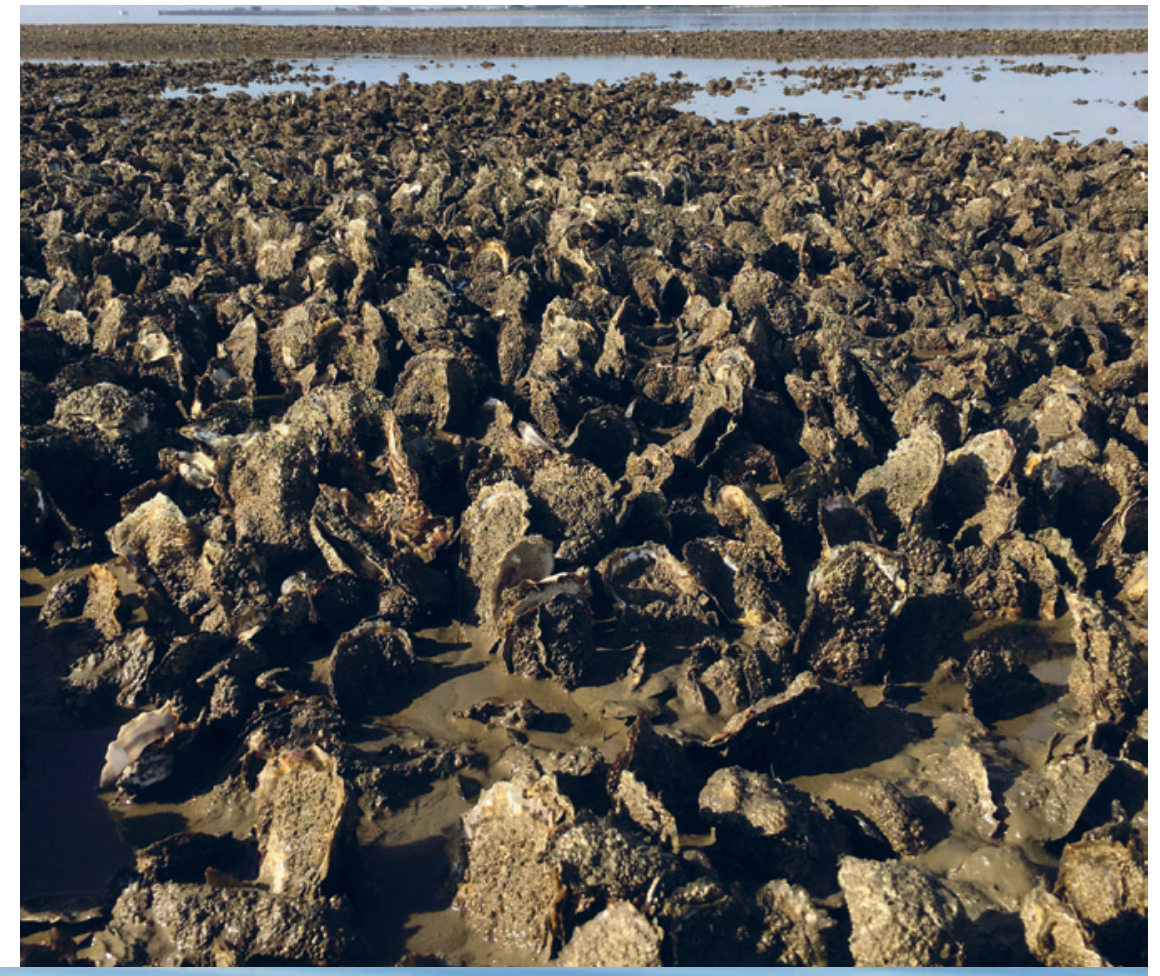

The eider duck is one of the birds feeding on shellfish. Can the Pacific oyster represent a threat?

Photo: Arne Duinker

$\downarrow$

-

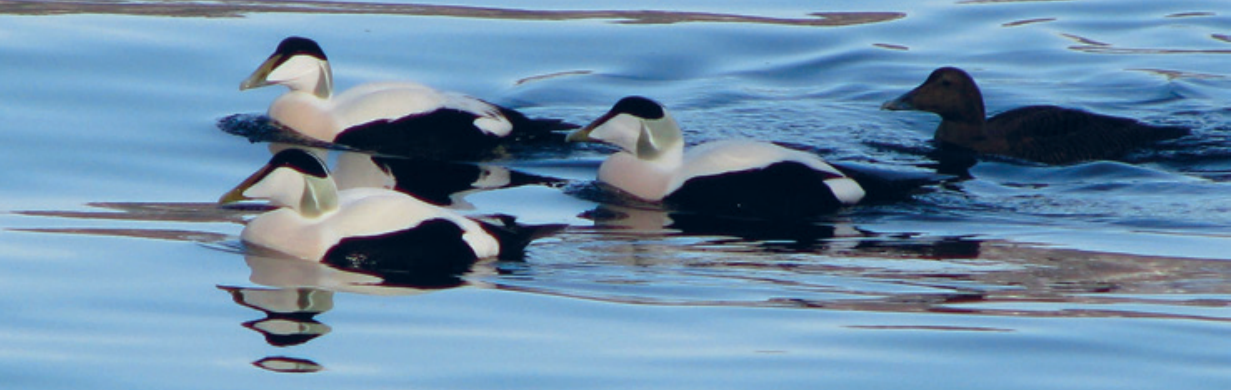

2

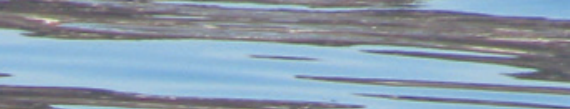

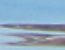




\section{The dispersal of oysters and their environmental effects}

The Pacific oyster, Crassostrea gigas, was introduced from South-East Asia to Europe. The last period of introductions - for aquaculture - started in 1964 and continued into the 1970s. The oyster dispersed from the aquaculture areas and established self-sustaining populations in shallow coastal areas. The species was established in Danish coastal waters in the mid-1990s and has colonized the Swedish west coast and the Norwegian coast north of Bergen. Studies show that the Nordic populations may have a more southern origin and have expanded northwards in a "stepping stone" pattern. While it is difficult to predict the species' final distribution range, it has recently and surprisingly - also expanded southwards to Øresund. Danish, Swedish and Norwegian marine scientists currently collaborate to monitor and predict the expansion and population dynamics in different Scandinavian coastal habitats.

The Pacific oyster may - when finding suitable habitats - build very dense populations and oyster reefs that alter the ecosystems. Scientists and managers alike have presumed that the establishments would cause a series of negative effects, e.g. changes in communities dominated by blue mussels, including effects on animals feeding on the mussels (like eider ducks). In some areas, the distribution of Pacific oysters overlaps the indigenous European flat oyster. This has raised a concern for whether the flat oyster populations will be invaded and overgrown by Pacific oysters.

In Germany and The Netherlands (where the ecosystem effects of Pacific oysters have been extensively studied) there has been a clear shift in the perception of the oysters, now focusing on positive effects such as the formation of so-called biogenic reefs. These reefs provide space and shelter for a high number of organisms, and thus contribute to a higher biodiversity. In Scandinavia, the effects also appear to be less negative than predicted, but the lack of baseline data makes such analyses uncertain. 


\section{Commercial exploitation of Pacific oysters in Scandinavia}

The Pacific oyster is one of the world's most important aquaculture species, with an annual production of several million tons to a large global market. In Europe, the largest productions are in France, Spain, the UK and Ireland. Since 2008, the main European production areas of Pacific oysters have been affected by diseases that limit production and income.

The presence of Pacific oysters in Scandinavia opens oportunities for establishment of new, commercial activities. Small-scale harvest, where oysters are collected by hand, sorted, depurated and sold on local markets, has already been initiated. In Denmark, small volumes of Pacific oysters are also delivered as by-catch from the dredge fishery for blue mussels in Limfjorden. In 2013, Dutch fishers established a sustainable (MSC-certified) oyster fishery that could provide a potential model for how to establish wild Pacific oyster harvest in Scandinavia.

New concepts for tourism such as oyster safaris have also been developed. Local businesses arrange visits to Pacific oyster

Pacific oysters are often attached to rocks. these oysters are difficult to harvest. It is important to estimate the harvestable part of the populations.

Photo: Nicolay Moe $\rightarrow$

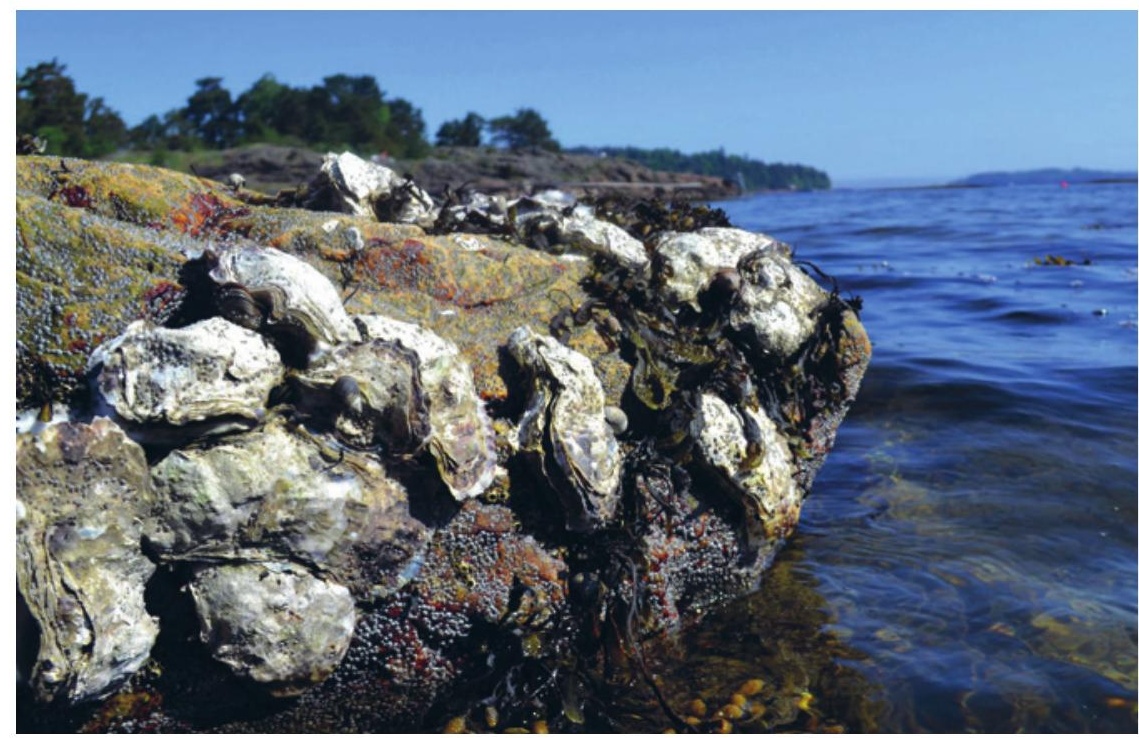


areas. The oyster-tour guides present the nature of the habitats and the effects of Pacific oysters on marine ecosystems. In some cases, the tourists may collect and bring oysters home. Several companies in Denmark have established concepts where participants on oyster trips harvest Pacific oysters for their own consumption. This is approved by the national food safety authorities, given that the trip operators do not contribute in the collection or opening of the oysters. Consumption and possible problems are thus on the tourists' own risk. Gastro-tourism has also been established, where the primary focus is on the Pacific oyster as a new, exclusive element in Scandinavian gastronomy. Oyster trophy week at Fanø in the Danish Wadden Sea is a good example of an event that has been important in the marketing of Pacific oysters.
Pacific oysters are considered an alien and invasive species, and traditional farming has so far not been allowed in the Scandinavian countries. Shellfish growers therefore currently work on developing farming concepts that reduce, or eliminate, the risk of oysters escaping from the farms. Future farming, including hatcheries, farms, and live storage of oysters before marketing, may also attract gastro-tourists. We envision future concepts where nature conservation, commercial harvest, production, and tourism, are integrated and creates added value to local economies. Tourists will get insight into the harvest and processing of oysters, visit the enterprises and get the opportunity to taste local oysters. This will contribute to the marketing of oysters as an attractive, safe, high quality product.

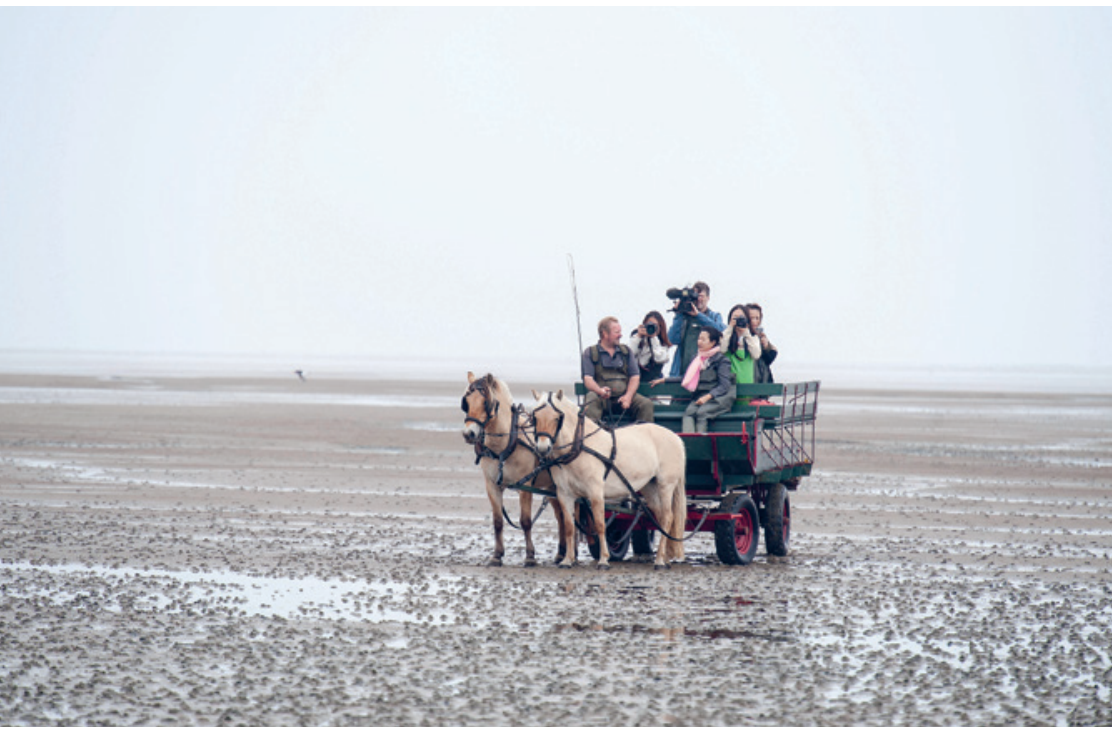

In the Danish Wadden

Sea, visitors can

experience the spectacular nature and see the Pacific oyster banks.

Photo: Scanpix.dk $\leftarrow$ 


\section{Regional oysters \\ - or the meaning of merroir}

"Do you want a Skagerrak oyster, a Wadden Sea oyster, or an Orust oyster" you may be asked at a restaurant in a few years - if the potential for the oyster industry is released. In countries where oysters are popular, like France and the U.S., the geographic origin of the oysters is an important marketing pitch. Oysters have different qualities and sensory profiles according to season and place of growth. The differences can be due to the level of sexual maturity, energy reserves, food sources and the salinity of the water. Such variation linked to area is well known from wine production and is then called terroir. In marine food production, including oysters, the term merroir denotes geographic origin. Pacific oysters have a sensory profile that is different from flat oysters. Marketing both species of Nordic oysters from different Nordic merriors may increase profitability of the oyster sector and should be further developed.

Flat and Pacific oysters of different origin displayed and for sale in the food halls in Copenhagen. Soon they may be supplemented with Nordic Pacific oysters from different regions?

Photo: Stein Mortensen $\rightarrow$

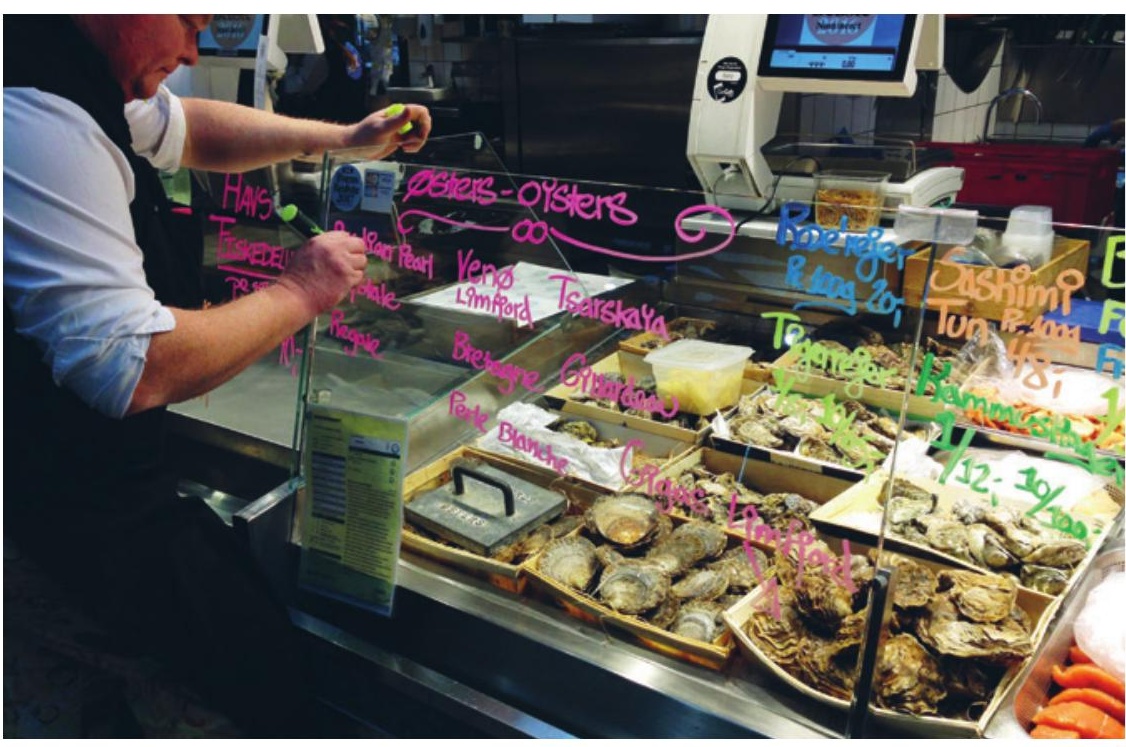




\section{Challenges}

The increasing interest in using the Nordic Pacific oysters as a new resource requires addressing several issues in order to realize its potential.

The first challenge is to establish the legal harvesting rights to Pacific oysters in shallow waters is crucial for the new companies that aim to exploit this resource. In Denmark, the oysters are state property, and anybody can harvest oysters for their own consumption. For commercial harvest, a permission from the fishery administration (Fiskeristyrelsen) is required. Additionally, the food authorities (Fødevarestyrelsen) must open production areas for harvest. This is based on an extensive sampling and control of the food quality. In

Sweden, the owner of the land facing the shoreline owns the oysters out to 200 meters from the shore. Thereby the landowner may give a permission to commercial harvest. In Norway, the right to exploit the resources on shallow water is not regulated by law, but according to decisions by the Norwegian Supreme Court, the landowner owns the resources out to two-meter depth at low tide. The public may collect oysters for their own consumption, but this may conflict with the exclusive right of the landowner if they have exploited the resource.
The second challenge is to implement systems to support the Achilles-heel of the shellfish industry: food safety. Sale of contaminated oysters causing consumer illness will give the oysters a bad reputation, damage consumer trust, and reduce profitability. To build up a large, stable, local market for Pacific oysters, it is important that the consumers trust the product, and have a reason to do so. Food health is also crucial for recreational harvesting - private, as well as during organized oyster trips. The food health authorities have a responsibility to ensure consumer safety, and all the Nordic countries are subject to the same EU regulation 178/2002 (General food law) and food hygiene regulations (e.g. 852/2004 and 853/2004). Oysters for human consumption must be controlled and approved according to these regulations. Due to the insufficient knowledge regarding the effect of norovirus, algal toxins and heavy metals on Pacific oysters, Nordic food safety authorities are not able to give appropriate advice to recreational harvesters. We stress the importance of establishing and expanding food safety research in the ongoing shellfish monitoring programs to ensure that authorities can give evidence-based advice. 
Surveillance of toxic algae and control of viruses, bacteria, algal toxins and other contaminants in oysters in the field will also be valuable for recreational harvest provided the results are made public. In the on-going work with developing commercial activities related to Pacific oysters, we need to enhance both knowledge and monitoring and develop adequate tools to secure consumer safety.

The third challenge for a budding Pacific oyster industry is access to a reliable natural resource. In practice this means access to robust populations of harvestable oysters and scientific advice on the effect of environmental fluctuations on population size. Studies from the northern part of the German Wadden Sea and Scandinavian coastal areas have shown that oysters in shallow areas have a low survival rate through winters with much sea ice. Warm summers may also result in summer mortalities due to infection with the ostreid herpesvirus (OsHV-1). Despite these "bottlenecks", the Nordic Pacific oyster populations have continued growing and we predict further geographic range expansion and population growth in the coming years. Continued mapping of new occurrences as well as expansion of the limited ongoing monitoring should therefore be a prioritized activity for Nordic authorities.
Nordic marine

scientists collaborate in the mapping and monitoring of Pacific oysters.

Photo: Åsa Strand $\rightarrow$

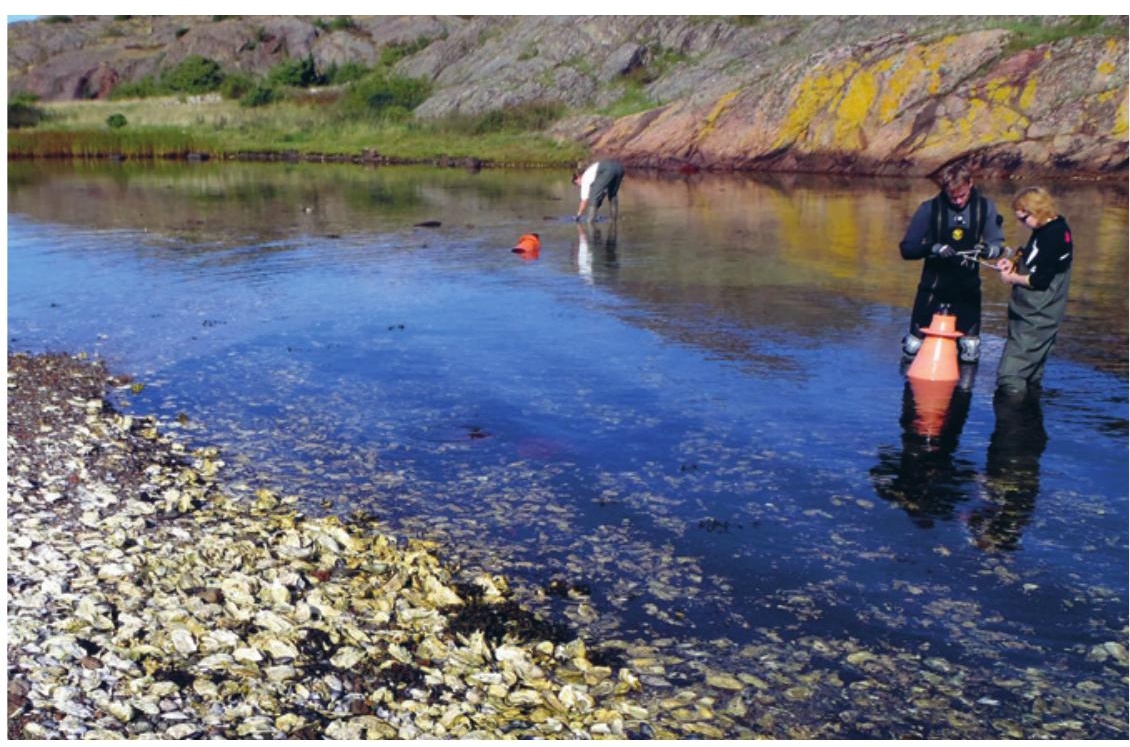




\section{Conclusions and recommendations}

The effort of establishing common Nordic models for mapping and monitoring Pacific oyster populations should be continued.

It is not possible to eradicate the Scandinavian Pacific oyster populations. We suggest that campaigns where oysters are removed from selected areas should be linked to monitoring of the populations and performed according to a common protocol. In this way, we take a scientific approach to management actions allowing us to evaluate and develop this activity further. Mapping and monitoring should include mussels and flat oysters, in order to build up datasets on these species and identify potential interactions with Pacific oysters.

The removed oysters should be used for human consumption or industrial processing, to obtain an optimal and responsible use of the resource.

Establishment of commercial oyster enterprises has great potential. Future development may include aquaculture, harvesting for human consumption, industrial products, and tourism. However, there are several challenges that must be overcome in order to release the potential this resource represents:

- In Norway and Sweden, the landowner has the right to harvest resources on shallow water. Legal issues linked to the right to harvest need to be clarified.

- Food safety is crucial for the consumers to trust the product. There is a need for more scientific data and development of methods for the establishment of a platform for quality control of Pacific oysters and consumer safety. Tools for proper risk evaluation should be developed within a Nordic cooperation framework to ensure optimal use of competence and existing data.

- The industry needs a model for storage of commercial volumes of harvested oysters, either at defined bottom culture areas or in landbased facilities.

- New business models combining nature management, harvesting, and tourism, should be developed. This could include partnerships between governmental authorities and private companies enabling commercial harvest activities to contribute to local management objectives. 


\section{Selected literature}

Laugen et al. 2015. The Pacific Oyster

(Crassostrea gigas) invasion in Scandina-

vian coastal waters in a changing climate:

impact on local ecosystem services. In Clode, J.C. (Ed.) Biological Invasions in Changing Ecosystems-Vectors, Ecological Impacts, Management and Predictions. De Gruyter Open, Berlin. Pp. 230-252.

Mortensen et al. 2017. Effects of a bio-invasion of the Pacific oyster, Crassostrea gigas (Thunberg, 1793) in five shallow water habitats in Scandinavia. Managing Biological Invasions 8: 543-552.

Mortensen et al. 2016. Summer mortalities and detection of ostreid herpesvirus microvariant in Pacific oyster Crassostrea gigas in Sweden and Norway. Diseases in Aquatic organisms. 117: 171-176.

Dolmer et al. 2014. The invasive Pacific oyster, Crassostrea gigas, in Scandinavian coastal waters: A risk assessment on the impact in different habitats and climate conditions. Fisken og Havet, 2: 1-67.

Strand et al. 2012. Impact of an icy winter on the Pacific oyster (Crassostrea gigas Thunberg, 1793) populations in Scandinavia. Aquatic Invasions, 7: 433-440. 


\section{Facts about Pacific oysters}

Latin: Crassostrea gigas

Family: Ostreidae

Life span: More than 20 years, up to more than $25 \mathrm{~cm}$ shell height, maximum weight more than 1.5 kilos.

Habitat: Lives attached to hard substrate, usually rocks or mussel shells, from the littoral zone down to a few meters depth.
Spawning area and period: Spawns during summer - dependent on high water temperatures. Fertilization occurs in the water body and larvae live as plankton for several weeks before settlement and permanent attachment.

Spreading: Large dispersal potential due to high number of larvae from each spawning female and a long planktonic phase, when larvae may be transported far by water currents.

Food: Bacteria, phytoplankton, other microorganisms and detritus.

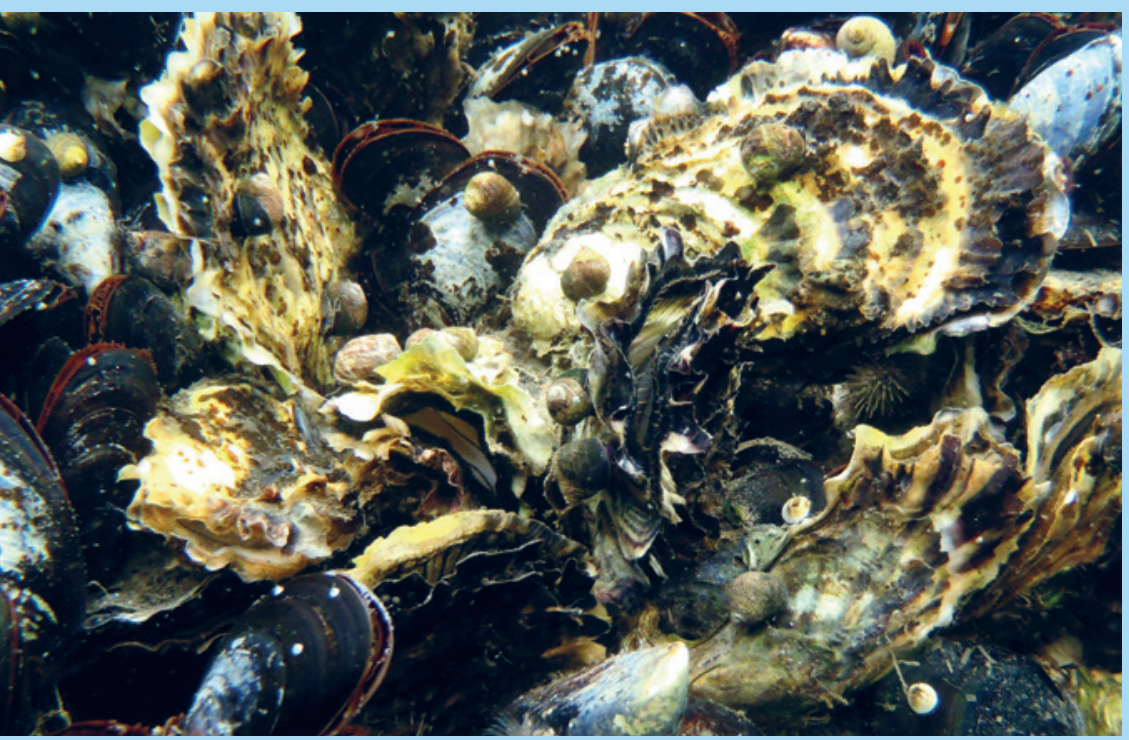

Pacific oysters on a mussel bed.

Photo: Åsa Strand $\leftarrow$ 


\section{Differences between Pacific and European flat oysters}

The European flat oysters, Ostrea edulis, is indigenous in Scandinavian waters. It lives below the littoral zone and down to a few meters depth. The shell shape is variable. Shells are usually round and flat, with an even brownish grey color, sometimes with a touch of green. The surface has fine curves and a flaky structure.

Pacific oysters often grow in the littoral zone, exposed to air during low tide. It has a rougher shell surface, with few deeply curved and sharp edges. The shells are typically long, with a cupped under-shell and a relatively flat uppershell. The shell surface often exhibits radial brownish or violet stripes.

It may be difficult to determine the species of oyster spat. Sometimes oysters at a few centimeter's size may also present a challenge. In most cases, it is easy to determine the species of oysters that are larger than a thumbnail based on shape, shell structure and color.
The indigenous flat oyster (left) is round, flat and has a surface with fine curves and a flaky structure. The Pacific oyster is usually longer, with a cupped under-shell and a relatively flat upper-shell. The surface is rough, often with dark stripes. stripes. In most cases it is easy to distinguish the two species.

Photo: Stein Mortensen $\rightarrow$

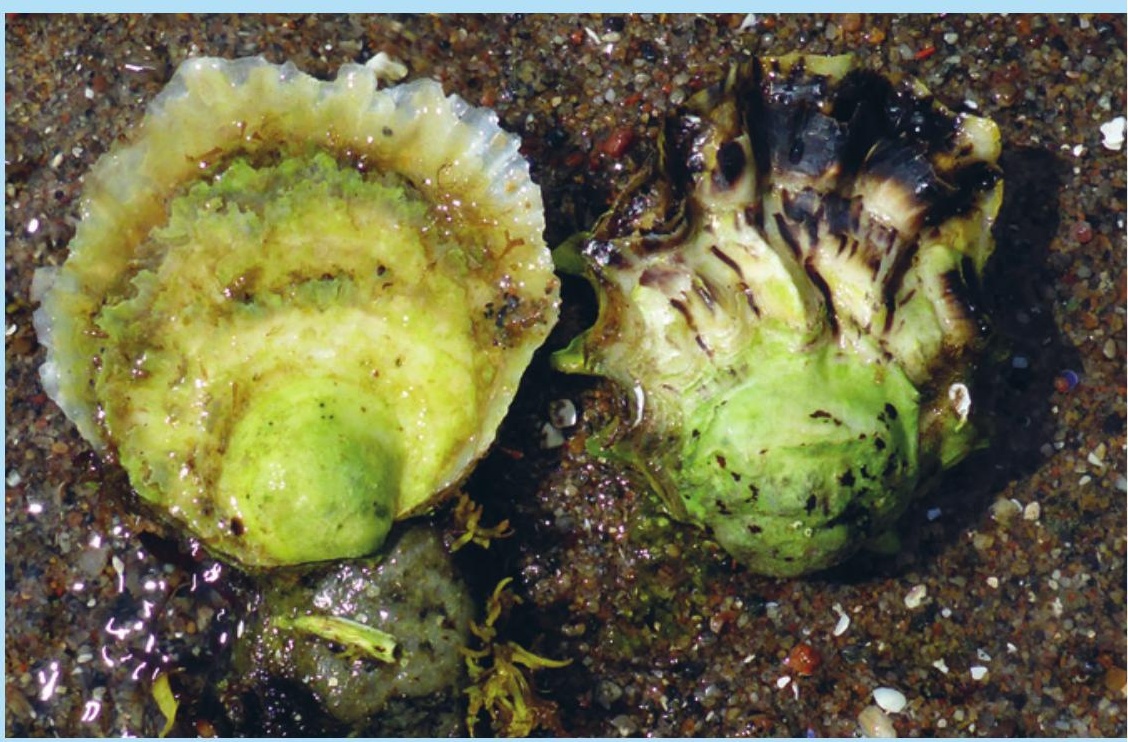




\section{Contact}

\section{Stein Mortensen}

Institute of Marine Research, Bergen,

Norway, project leader

+4795755419 / stein.mortensen@hi.no

\section{Per Dolmer}

Orbicon, Viby J, Denmark

+45 21347781 / pdol@orbicon.dk

\section{Åsa Strand}

IVL Svenska Miljöinstitutet, Göteborg,

Sweden

+4610788 6605 / asa.strand@ivl.se

\section{Lars-Johan Naustvoll}

Institute of Marine Research, Flødevigen

Norway

+4795246102/larsjn@hi.no

\section{Ane Timenes Laugen}

University of Agder, Department of

Natural Sciences, Centre for Coastal

Research, Kristiansand, Norway

+47 38141451 / ane.t.laugen@uia.no 


\section{Harvesting Pacific oysters}

This publication is a product of "Harvesting Pacific oysters", a project that was carried out in the period 2017-2019. The main aim has been to clarify crucial questions and scientific matters related to harvesting Scandinavian Pacific oysters - linked to both removal campaigns and exploitation as a new food resource. The project was launched during the Norwegian presidency of the Nordic Council of Ministers in 2017. 


\section{Nordic Council of Ministers}

\section{Nordens Hus}

Ved Stranden 18

DK-1061 Copenhagen

www.norden.org

The Pacific oyster has established populations in Scandinavian coastal waters. The species is considered alien and invasive and dense populations may cause changes in benthic habitats. It is, however, one of the world's most important aquaculture species, and there is a growing interest in using the Scandinavian populations as a new marine resource.

To release the commercial potential, there is urgent need for a better understanding of the oyster's effect on the ecosystem and a clarification of legal matters, as well as establishment of management practices for harvesting and marketing these oysters.

This Policy brief gives a summary of the status for the Pacific oyster in Scandinavia and presents recommendations for the future work and management of Pacific oysters in the Nordic countries. 